

\title{
The Kreps-Scheinkman game in mixed duopolies*
}

\author{
Barna Bakó $^{\dagger} \quad$ Attila Tasnádi ${ }^{\ddagger}$
}

July 15, 2014

\begin{abstract}
In this paper we extend the results of Kreps and Scheinkman (1983) to mixedduopolies. We show that quantity precommitment and Bertrand competition yield Cournot outcomes not only in the case of private firms but also when a public firm is involved.
\end{abstract}

Keywords: Mixed duopoly, Cournot, Bertrand-Edgeworth.

JEL Classification Number: D43, H44, L13, L32.

\section{Introduction}

One of the most cited papers in the oligopoly related theoretical literature is that of Kreps and Scheinkman (1983). In this seminal paper, the authors prove that Cournot competition leads to an outcome which is equivalent to the equilibrium of a two-stage game, where there is a simultaneous capacity choice after which price competition occurs. This is an important result given the popularity of the Cournot model, as it solves the price-setting problem represented by the mythical Walrasian auctioneer in quantity-setting games.

Since then, many papers dealt with this equivalence trying to exploit its boundaries. Firstly, Osborne and Pitchik (1986) relaxed the assumptions imposed on the demand and cost functions, while Davidson and Deneckere (1986) challenged the validity of the result

\footnotetext{
${ }^{*}$ We would like to thank the participants of the Oligo 2014 Workshop in Rome for helpful comments.

${ }^{\dagger}$ Department of Microeconomics, Corvinus University of Budapest and MTA-BCE „Lendület” Strategic Interactions Research Group, 1093 Budapest, Fơvám tér 8., e-mail: barna.bako@uni-corvinus.hu. This research was supported by the European Union and the State of Hungary, co-financed by the European Social Fund in the framework of TÁMOP-4.2.4.A/ 2-11/1-2012-0001 'National Excellence Program'.

‡Department of Mathematics, Corvinus University of Budapest and MTA-BCE „Lendület” Strategic Interactions Research Group, 1093 Budapest, Fővám tér 13-15., e-mail: attila.tasnadi@uni-corvinus.hu. Financial support from the Hungarian Scientific Research Fund (OTKA K-101224) is gratefully acknowledged. (Corresponding author)
} 
by replacing the efficient rationing rule used by Kreps and Scheinkman (1983) with other rationing rules such as the proportional rationing rule and showed that the result does not hold for a certain set of parameters. ${ }^{1}$ Deneckere and Kovenock (1996) showed that even under the efficient rationing rule the Kreps and Scheinkman (1983) result does not remain valid if the unit costs of the second stage are sufficiently asymmetric. Lepore (2009) determined a sufficient condition under which the Kreps and Scheinkman (1983) result still holds in case of asymmetric cost functions and different rationing rules. Furthermore, Reynolds and Wilson (2000) introduced demand uncertainty to the model and pointed out that equilibrium capacities are not equal to the Cournot quantities. In their model the uncertainty prevails only at the time when firms choose capacities. However, at the beginning of the second stage the demand is observed and prices are set in a deterministic way. $^{2}$ On the other hand, when uncertainty persists in the price-setting stage, de Frutos and Fabra (2011) illustrated that under certain assumptions the total welfare is equivalent to the Cournot case, yet the capacity levels are asymmetric even when firms are ex-ante identical.

Boccard and Wauthy (2000 and 2004) generalized Kreps and Scheinkman's (1983) result to multi-player markets assuming efficient rationing and identical cost functions. Moreover, under similar conditions Loertscher (2008) proved that the equivalence result holds when firms compete in the input and the output market at the same time. More recently, Wu, Zhu and Sun (2012) generalized the celebrated equivalency result by relaxing the assumptions imposed on the demand and cost functions.

In this paper we extend the Kreps and Scheinkman (1983) result to the case in which a private firm competes with a public firm, that is, to the case of a so-called mixed duopoly. The idea of mixed oligopolies as a possible form of regulation was introduced by Merrill and Schneider (1966). Its relevance stems from the possibility of increasing social welfare through the presence of a public firm in the market. Indeed, it is common to observe public and private firms competing in the same industry. ${ }^{3}$

As for studies of mixed oligopolies, the Cournot game was examined by Harris and Wiens (1980), Beato and Mas-Colell (1984), Cremer, Marchand and Thisse (1989) and de Fraja and Delbono (1989). Balogh and Tasnádi (2012) studied the price-setting game for given capacities. Therefore, in order to extend the Kreps and Scheinkman (1983) result for mixed duopolies, the solution of the capacity game is required. For linear demand and cost functions this solution was given by Bakó and Tasnádi (2014), but that requires the private firm to be more cost-efficient than the public firm. However, as we will see, in the

\footnotetext{
${ }^{1}$ For more about rationing rules see, for instance, Vives (1999) or Wolfstetter (1999).

${ }^{2}$ Lepore (2012) generalized Reynolds and Wilson (2000) results for a wide range of demand uncertainties with different rationing rules.

${ }^{3} \mathrm{~A}$ few notable examples for public firms are: the Kiwibank, which is a state owned commercial bank in New-Zealand; Amtrak, the railway company in USA; the Indian Drugs and Pharmaceuticals Limited, which is owned by the Indian Government; the Norwegian Statoil, owned in $60 \%$ by the national government; or in the aviation industry Aeroflot, Air New-Zealand, Finnair, Qatar Airways are all owned in majority by their national government.
} 
case of strictly convex cost and concave demand functions either any of the two firms can have a cost advantage or the firms can have the same cost functions in order to obtain the Kreps and Scheinkman (1983) result. A similar case distinction was made by Tomaru and Kiyono (2010), while investigating an analogous mixed timing game; in particular, they analyzed the strictly convex case and mentioned in a footnote that the linear case requires the additional assumption of a more efficient private firm for obtaining their result.

In the remainder of the paper we first present our setup and summarize known results on the mixed Cournot game followed by known results on the price-setting game. Employing these results, we determine the equilibrium capacity levels and conclude.

\section{Preliminaries}

We consider mixed duopolies in which two firms, $A$ and $B$, produce perfectly substitutable products. Firm $\mathrm{A}$ is a private firm and maximizes its profit, while firm $\mathrm{B}$ is a public firm and aims to maximize total surplus.

The market demand function is given by $D$ on which we impose the following assumptions.

Assumption 1. (i) D intersects the horizontal axis at quantity a and the vertical axis at price $b$; (ii) $D$ is strictly decreasing, concave and twice-continuously differentiable on $(0, b)$; (iii) $D$ is right-continuous at 0 and left-continuous at $b$; and $(i v) D(p)=0$ for all $p \geq b$.

We shall denote by $P$ the inverse demand function, that is $P(q)=D^{-1}(q)$ for $0<q \leq a$, $P(0)=b$, and $P(q)=0$ for all $q>a$.

The firms' cost functions are given by $C_{i}(i=A, B)$, which satisfy the following assumptions.

Assumption 2. (i) $C_{i}(0)=0 ;($ ii $) C_{i}^{\prime}(0)<b$ and (iii) $C_{i}$ is strictly increasing, strictly convex and twice-continuously differentiable on $[0, \infty)$.

Hence, we impose assumptions on the demand and cost functions similar to Kreps and Scheinkman (1983). The two main differences are that we allow for non identical cost functions and that we require strictly convex cost functions instead of just convex cost functions.

\subsection{The mixed Cournot duopoly}

The mixed Cournot duopoly has been investigated extensively in the literature. This subsection describes the model and summarizes the results obtained by Tomaru and Kiyono (2010). The private firm is a profit-maximizer and its profit function is given by

$$
\pi_{A}^{C}\left(q_{A}, q_{B}\right)=P\left(q_{A}+q_{B}\right) q_{A}-C_{A}\left(q_{A}\right)
$$


while the public firm intends to maximize social welfare, hence its objective function is given by

$$
\pi_{B}^{C}\left(q_{A}, q_{B}\right)=\int_{0}^{q_{A}+q_{B}} P(z) d z-C_{A}\left(q_{A}\right)-C_{B}\left(q_{B}\right)
$$

We illustrate the objective function of the public firm by the following example.

Example 1. Let $P(q)=1-p, C_{A}\left(q_{A}\right)=\frac{1}{6} q_{A}^{2}$ and $C_{B}\left(q_{B}\right)=\frac{1}{4} q_{B}^{2}$.

The social welfare for this example is depicted in Figure 1 by the shaded area when firms produce quantities $q_{A}=1 / 2$ and $q_{B}=1 / 3$.

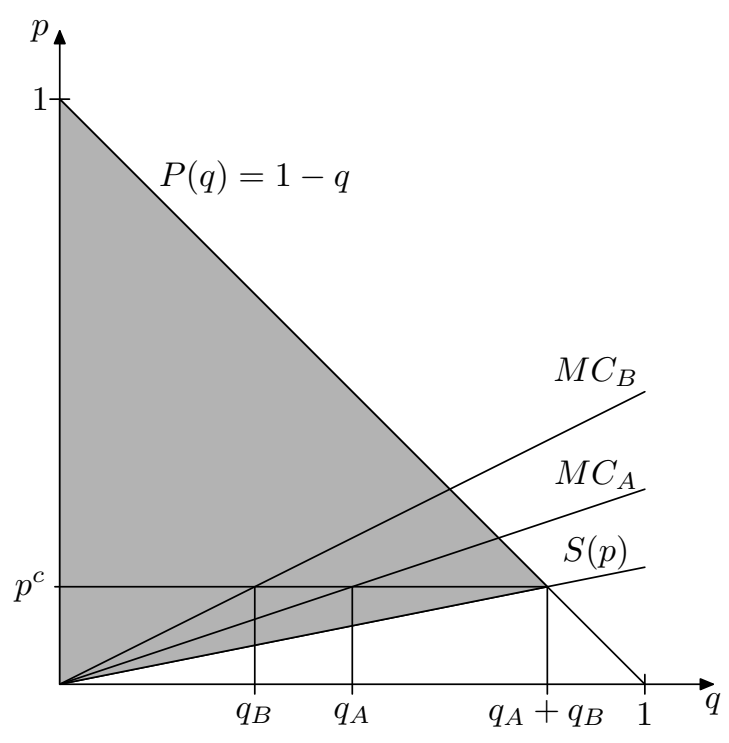

Figure 1: Social welfare in the mixed Cournot duopoly.

In equilibrium firms produce quantities, which satisfy the equation system derived from the first-order conditions:

$$
\begin{aligned}
& \frac{\partial \pi_{A}^{C}\left(q_{A}, q_{B}\right)}{\partial q_{A}}=P^{\prime}\left(q_{A}+q_{B}\right) q_{A}+P\left(q_{A}+q_{B}\right)-C_{A}^{\prime}\left(q_{A}\right)=0, \\
& \frac{\partial \pi_{B}^{C}\left(q_{A}, q_{B}\right)}{\partial q_{B}}=P\left(q_{A}+q_{B}\right)-C_{B}^{\prime}\left(q_{B}\right)=0 .
\end{aligned}
$$

From Tomaru and Kiyono (2010) it follows that under Assumptions 1 and 2 the equation system (3) has a unique solution and that the mixed Cournot duopoly has a unique equilibrium in pure strategies. In particular, we impose the concavity of the demand function by Assumption 1, which implies their Assumption 3. A minor difference in the imposed assumptions is that Tomaru and Kiyono (2010) assume demand curves not intersecting the horizontal axis in contrast to condition (i) of Assumption 1. However, this does not change 
the fact that the firms' reaction functions are differentiable, strictly decreasing and posses derivatives larger than -1 whenever they are positive. In our setting both reaction curves cut the respective axis at the horizontal intercept of the demand curve. Therefore, taking also point (ii) of Assumption 2 into account, the two firms' reaction curves have a unique interception point. ${ }^{4}$

Coming back to Example 1, it can be verified that the Nash equilibrium of the mixed Cournot duopoly game is given by $q_{A}=1 / 5$ and $q_{B}=8 / 15$, while the equilibrium of the standard Cournot duopoly is given by $q_{A}=9 / 29$ and $q_{B}=8 / 29$. Clearly, the mixed version of the Cournot duopoly results in larger outputs and social welfare.

\subsection{The price-setting game}

In this section we briefly review the result obtained by Balogh and Tasnádi (2012) on the simultaneous-move mixed Bertrand-Edgeworth duopoly with capacity constraints in which firms can produce up to their capacity levels $k_{A}, k_{B} \in(0, a]$ at zero unit costs after setting their prices simultaneously. ${ }^{5}$ Taking capacities as given, firms choose their prices $p_{i} \in[0, b]$ $(i=A, B)$ to maximize their payoffs.

To determine the firms' demand and profit functions, we employ the efficient rationing rule. ${ }^{6}$ Let us denote the market clearing price by $p^{c}$ and firm $i$ 's $(i=A, B)$ unique profitmaximizing price on its residual demand curve $D_{i}^{r}\left(p_{i}\right)=\max \left\{0, D\left(p_{i}\right)-k_{j}\right\}$ by $p_{i}^{m}$ in case of $k_{j}<a$, where $D_{i}^{r}$ equals the demand faced by firm $i$ if it is the high-price firm $(j \neq i){ }^{7}$ Let $\pi_{i}^{r}\left(p_{i}\right)=p_{i} D_{i}^{r}\left(p_{i}\right)$. Any price leads to zero profits on $\pi_{i}^{r}$ in case of $k_{j}=a$, and therefore, for notational convenience we define $p_{i}^{m}$ by 0 in this case. Hence,

$$
p^{c}=P\left(k_{A}+k_{B}\right) \quad \text { and } \quad p_{i}^{m}=\min \left(\arg \max _{p \in[0, b]} \pi_{i}^{r}(p)\right) .
$$

Furthermore, let $p_{i}^{d}$ be the lowest price satisfying equation

$$
p_{i}^{d} \min \left\{k_{i}, D\left(p_{i}^{d}\right)\right\}=\pi_{i}^{r}\left(p_{i}^{m}\right),
$$

whenever this equation has a solution. ${ }^{8}$ Thus, by choosing $p_{i}^{d}$ and selling $\min \left\{k_{i}, D\left(p_{i}^{d}\right)\right\}$,

\footnotetext{
${ }^{4}$ See also Amir and De Feo (2014, Section 5).

${ }^{5}$ The main assumption is that firms have identical unit costs when production takes place. For the case of asymmetric unit costs in the price-setting stage we refer to Deneckere and Kovenock (1996).

${ }^{6}$ Suppose firm $i$ charges the lowest price $\left(p_{i}\right)$. If $k_{i}<D\left(p_{i}\right)$, not all consumers who want to buy from firm $i$ are able to do so. The efficient rationing rule suggests that the most eager consumers are the ones who are able to purchase from firm $i$, that is the residual demand function of firm $j \neq i$ can be obtained by shifting the market demand function to the left by $k_{i}$. This rationing rule is called efficient because it maximizes consumer surplus. For more details we refer to Vives (1999) or Wolfstetter (1999).

${ }^{7}$ Deneckere and Kovenock (1992) define a similar price to $p_{i}^{m}$; however, in a slightly different way since they include firm $i$ 's capacity constraint in the profit-maximization problem with respect to $D_{i}^{r}$.

${ }^{8}$ The equation defining $p_{i}^{d}$ has a solution if and only if $p_{i}^{m} \geq p^{c}$, which will be the case in our analysis when we will refer to $p_{i}^{d}$.
} 
firm $i$ generates the same amount of profit as it would by setting $p_{i}^{m}$ and serving its residual demand.

Now we are coming back to definitions of the firms' demand and profit functions. The firm which sets the lower price faces the market demand, while the firm with the higher price has a residual demand of $D_{i}^{r}\left(p_{i}\right)=\max \left\{0, D\left(p_{i}\right)-k_{j}\right\}$. In the case of $p_{A}=p_{B}$ the following tie-breaking rule is used for mixed duopolies: If prices are higher than a threshold $\bar{p}$, which equals either $p_{A}^{d}$ if $p_{A}^{m} \geq p^{c}$ or 0 otherwise, then the demand is allocated in proportion of the firms' capacities, however if prices are not higher than $\bar{p}$, the public firm allows the private firm to serve the entire demand up to its capacity level in order to encourage the private firm to set lower prices. ${ }^{9}$ Formally,

$$
\Delta_{i}\left(p_{i}, p_{j}\right)=\left\{\begin{array}{lll}
\min \left\{k_{i}, D\left(p_{i}\right)\right\} & \text { if } & p_{i}<p_{j}, \\
\min \left\{k_{i}, D_{i}^{r}\left(p_{i}\right)\right\} & \text { if } p_{i}>p_{j}, \\
\min \left\{k_{i}, \frac{k_{i}}{k_{i}+k_{j}} D\left(p_{i}\right)\right\} & \text { if } \quad p_{i}=p_{j}>\bar{p}, \\
\min \left\{k_{i}, D\left(p_{i}\right)\right\} & \text { if } \quad p_{i}=p_{j} \leq \bar{p} \text { and } i=A, \\
\min \left\{k_{i}, D_{i}^{r}\left(p_{i}\right)\right\} & \text { if } \quad p_{i}=p_{j} \leq \bar{p} \text { and } i=B .
\end{array}\right.
$$

The firms' objective functions are given by

$$
\pi_{A}^{B}\left(p_{A}, p_{B}\right)=p_{A} \Delta_{A}\left(p_{A}, p_{B}\right)
$$

and

$$
\pi_{B}^{B}\left(p_{A}, p_{B}\right)=\int_{0}^{\min \left\{k_{j}, \max \left\{0, D\left(p_{j}\right)-k_{i}\right\}\right\}} R_{j}(q) d q+\int_{0}^{\min \left\{k_{i}, a\right\}} P(q) d q,
$$

where $0 \leq p_{i} \leq p_{j} \leq b$ and $R_{j}(q)=\left(D_{j}^{r}\right)^{-1}(q)$.

For Example 1, we illustrate firms' profits and consumers' surplus in Figure 2. The lightest-grey triangle corresponds to the surplus realized by the consumers who purchase the product at the highest price, while the light-grey area depicts the surplus realized by the other consumers. On the producers' side, the low-price firm's surplus is given by the darkest-grey rectangular and the high-price firm's surplus by the dark-grey area. Note that total welfare is determined by the higher price, except when the residual demand equals zero at the higher price.

The solution of the price-setting game can be found in Balogh and Tasnádi (2012, Propositions 2 and 5). If $p_{A}^{m} \geq p^{c}$, the equilibrium prices $\left(p_{A}^{*}, p_{B}^{*}\right)$ are given by

$$
p_{A}^{*}=p_{B}^{*}=p_{A}^{d}
$$

\footnotetext{
${ }^{9}$ For prices higher than $\bar{p}$ we could have used many other tie-breaking rules, e.g. the tie-breaking rule used by Kreps and Scheinkman (1983), the only requirement is that none of the firms should have the possibility to sell its entire capacity. For more about the employed tie-breaking rule we refer to Balogh and Tasnádi (2012).
} 


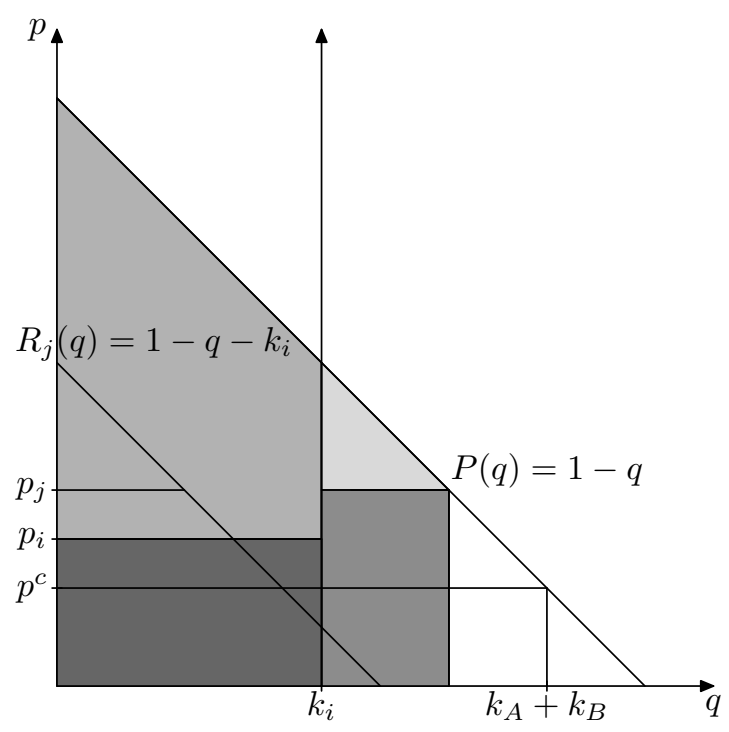

Figure 2: Total welfare in the price-setting game

or

$$
\left\{\left(p_{A}^{*}, p_{B}^{*}\right) \in[0, b]^{2} \mid p_{A}^{*}=p_{A}^{m} \quad \text { and } \quad p_{B}^{*} \leq p_{A}^{d}\right\} .
$$

Moreover, if $k_{B} \leq k_{A}$ and $k_{B} \leq D\left(p^{M}\right)$, where $p^{M}$ is the price set by a monopolist without capacity constraints, i.e. $p^{M}=\arg \max _{p \in[0, P(0)]} p D(p)$, then price profiles

$$
\left\{\left(p_{A}^{*}, p_{B}^{*}\right) \in[0, b]^{2} \mid p_{A}^{*}=\max \left\{p^{M}, P\left(k_{A}\right)\right\} \quad \text { and } \quad p_{B}^{*}>\max \left\{p^{M}, P\left(k_{A}\right)\right\}\right\}
$$

are also equilibrium profiles.

If, however $p_{A}^{m}<p^{c}$, then the set of equilibrium profiles equals

$$
\left\{\left(p_{A}^{*}, p_{B}^{*}\right) \in[0, b]^{2} \mid p_{A}^{*}=p^{c} \quad \text { and } \quad p_{B}^{*} \leq p^{c}\right\} .
$$

Henceforward, we will refer to the first case $\left(p_{A}^{m} \geq p^{c}\right)$ as the strong private firm case and to the latter $\left(p_{A}^{m}<p^{c}\right)$ as the weak private firm case.

In the strong private firm case the equilibrium given by (7) Pareto dominates the one given by (8). Furthermore, the not always existing equilibria given by (9) describe situations when the public firm is inactive, which would imply that the public firm does not care about consumer surplus and its own profits. Therefore in what follows we consider (7) as the solution of the price-setting game in the strong private firm case. ${ }^{10}$

Hence, firms' equilibrium quantities are be given by

$$
q_{A}^{*}=\min \left\{k_{A}, D\left(p_{A}^{*}\right)\right\} \quad \text { and } \quad q_{B}^{*}=\min \left\{k_{B}, D_{B}^{r}\left(p_{B}^{*}\right)\right\} .
$$

\footnotetext{
${ }^{10}$ For more details on selecting $(7)$ as the most plausible equilibrium we refer to Balogh and Tasnádi (2012).
} 


\section{The mixed Kreps and Scheinkman game}

In this section we determine the subgame perfect Nash equilibrium of the following twostage game:

1. firms' choose their capacity levels $k_{A}, k_{B} \in[0, a]$ simultaneously at respective costs $C_{A}\left(k_{A}\right), C_{B}\left(k_{B}\right)$ and

2. firms play the mixed price-setting game discussed in Subsection 2.2.

We will refer to this capacity then price game as the mixed Kreps and Scheinkman game.

Theorem 1. Under Assumptions 1, 2 and efficient rationing

- the mixed Cournot duopoly has a unique equilibrium $\left(q_{A}^{*}, q_{B}^{*}\right)$,

- in a subgame perfect equilibrium, assuming that in case of a strong private firm in the second stage (7) is played, the mixed Kreps and Scheinkman game has a unique first-stage equilibrium $\left(k_{A}^{*}, k_{B}^{*}\right)$ and

- $\left(q_{A}^{*}, q_{B}^{*}\right)=\left(k_{A}^{*}, k_{B}^{*}\right)$.

Proof. We divide our proof into five steps.

Step 1. We identify and describe the capacity regions in which the first-stage profit functions are defined by different expressions.

The equilibrium prices of the subgame given by (7) or (10) are functions of the firststage capacity decisions. Based on Berge's Maximum Theorem the maximum residual profit $\pi_{A}^{r}\left(p_{A}^{m}\right)$ is continuous in $\left(k_{A}, k_{B}\right)$ and since $p_{A}^{m}$ is unique it is a continuous function of $\left(k_{A}, k_{B}\right)$ as well. ${ }^{11}$ Therefore, $p_{A}^{d}$ is continuous in $\left(k_{A}, k_{B}\right)$ on subregion

$$
\left\{\left(k_{A}, k_{B}\right) \in[0, a]^{2} \mid p_{A}^{m}\left(k_{B}\right) \geq P\left(k_{A}+k_{B}\right)\right\},
$$

i.e whenever $p_{A}^{d}$ is well defined. ${ }^{12}$

Let us denote the set of capacity-profiles compatible with the weak private firm case by

$$
K^{c}=\left\{\left(k_{A}, k_{B}\right) \in[0, a]^{2} \mid p_{A}^{m}\left(k_{B}\right) \leq P\left(k_{A}+k_{B}\right)\right\}
$$

and with the strong private firm case by

$$
K^{d}=\left\{\left(k_{A}, k_{B}\right) \in[0, a]^{2} \mid p_{A}^{m}\left(k_{B}\right)>P\left(k_{A}+k_{B}\right)\right\} .
$$

Notice that $K^{c}$ is a closed set, since $p_{A}^{m}$ and $P$ are continuous.

\footnotetext{
${ }^{11}$ In fact, $p_{A}^{m}$ is independent from $k_{A}$, and therefore, in what follows we consider $p_{A}^{m}$ as a single variable function.

${ }^{12}$ Note that, if $p_{A}^{m}=p^{c}$, then $p_{A}^{d}=p^{c}$.
} 
We need to consider $p_{A}^{m}$, which by definition is the price maximizing $p\left(D(p)-k_{B}\right) .{ }^{13}$ That is, $p_{A}^{m}$ satisfies the following first-order condition:

$$
\frac{\partial \pi_{A}^{r}}{\partial p}\left(p_{A}^{m}\right)=p_{A}^{m} D^{\prime}\left(p_{A}^{m}\right)+D\left(p_{A}^{m}\right)-k_{B}=0
$$

Based on Assumption 1, $\frac{\partial \pi_{A}^{r}}{\partial p}$ is strictly decreasing, $p_{A}^{m}$ is unique and, as already mentioned, independent from $k_{A}$.

The boundary curve dividing the strong and the weak private firm case is given by $p_{A}^{m}\left(k_{B}\right)=P\left(k_{A}+k_{B}\right)$. For any given $k_{B}$, if $k_{A}$ satisfies $p_{A}^{m}\left(k_{B}\right)=P\left(k_{A}+k_{B}\right)$, then for every capacity $k_{A}^{\prime} \in\left[0, k_{A}\right)$ we have that $p_{A}^{m}\left(k_{B}\right)<P\left(k_{A}^{\prime}+k_{B}\right)$, which is the case because the left-hand side is independent of $k_{A}^{\prime}$ and the right-hand side is decreasing in $k_{A}^{\prime}$. Thus, for every $k_{B}$ there exists a $k_{A}^{\prime \prime}$ such that the projection of $K^{c}$ at $k_{B}$ equals $\left[0, k_{A}^{\prime \prime}\right]$.

We show that the boundary curve, which is defined by the implicit equation $p_{A}^{m}\left(k_{B}\right)=$ $P\left(k_{A}+k_{B}\right)$, is strictly decreasing in $\left(k_{A}, k_{B}\right)$ space. The implicit equation defining the boundary curve can be expressed as

$$
D^{\prime}\left(P\left(k_{A}+k_{B}\right)\right) P\left(k_{A}+k_{B}\right)+k_{A}+k_{B}-k_{B}=0
$$

from which under Assumption 1 by the Implicit Function Theorem we obtain

$$
\begin{aligned}
\frac{\partial k_{B}}{\partial k_{A}} & =-\frac{D^{\prime \prime}\left(P\left(k_{A}+k_{B}\right)\right) P^{\prime}\left(k_{A}+k_{B}\right) P\left(k_{A}+k_{B}\right)+D^{\prime}\left(P\left(k_{A}+k_{B}\right)\right) P^{\prime}\left(k_{A}+k_{B}\right)+1}{D^{\prime \prime}\left(P\left(k_{A}+k_{B}\right)\right) P^{\prime}\left(k_{A}+k_{B}\right) P\left(k_{A}+k_{B}\right)+D^{\prime}\left(P\left(k_{A}+k_{B}\right)\right) P^{\prime}\left(k_{A}+k_{B}\right)} \\
& =-1-\frac{1}{P^{\prime}\left(k_{A}+k_{B}\right)\left(D^{\prime \prime}\left(P\left(k_{A}+k_{B}\right)\right) P\left(k_{A}+k_{B}\right)+D^{\prime}\left(P\left(k_{A}+k_{B}\right)\right)\right)}<0 .
\end{aligned}
$$

Furthermore, let us divide $K^{d}$ into subsets

$$
\begin{aligned}
& K_{1}^{d}=\left\{\left(k_{A}, k_{B}\right) \in K^{d} \mid k_{A} \leq D\left(p_{A}^{d}\left(k_{A}, k_{B}\right)\right)\right\} \text { and } \\
& K_{2}^{d}=\left\{\left(k_{A}, k_{B}\right) \in K^{d} \mid k_{A}>D\left(p_{A}^{d}\left(k_{A}, k_{B}\right)\right)\right\},
\end{aligned}
$$

where $p_{A}^{d}$ has been defined in Subsection 2.2 for given capacity profiles lying in $K^{d}$. Henceforth, we omit the arguments $k_{A}$ and $k_{B}$ of functions $p_{A}^{d}, p_{A}^{m}$ and $p^{c}$ for notational convenience.

We turn to determining the projection of the set $K_{1}^{d}$ at an arbitrarily fixed value of $k_{B}$. The condition $k_{A} \leq D\left(p_{A}^{d}\right)$ defining $K_{1}^{d}$ is equivalent to $P\left(k_{A}\right) \geq p_{A}^{d}$, where by definition $p_{A}^{d}=\left(p_{A}^{m}\left(D\left(p_{A}^{m}\right)-k_{B}\right)\right) / k_{A}$ within $K_{1}^{d}$. We thus define:

$$
f\left(k_{A}\right)=\frac{p_{A}^{m}\left(D\left(p_{A}^{m}\right)-k_{B}\right)}{k_{A}}-P\left(k_{A}\right)=\frac{c}{k_{A}}-P\left(k_{A}\right)
$$

\footnotetext{
${ }^{13}$ Bear in mind that we have defined $p_{A}^{m}$ separately for the case of $k_{B}=a$, ensuring that $p_{A}^{m}$ is leftcontinuous at $a$.
} 
where $c=\pi_{A}^{r}\left(p_{A}^{m}\right)$ depends only on $k_{B} .{ }^{14}$ While the sign of $f^{\prime}$ is ambiguous, $f^{\prime \prime}>0$, that is $f$ is strictly convex. Moreover, $\lim _{k_{A} \rightarrow 0^{+}} f\left(k_{A}\right)=\infty$ and $f(a)>0$. Let us denote the capacity level on the boundary of sets $K^{c}$ and $K^{d}$ at $k_{B}$ by $k_{A}^{\prime}$, that is $p_{A}^{m}\left(k_{B}\right)=P\left(k_{A}^{\prime}+k_{B}\right)$. It can be shown that $f\left(k_{A}^{\prime}\right)<0$, thus for any given $k_{B}$ there exists a $k_{A}^{\prime \prime}$ so that the projection of the set $K_{1}^{d}$ equals $\left(k_{A}^{\prime}, k_{A}^{\prime \prime}\right]$. Based on these results for any given $k_{B}$ the private firms capacities can be partitioned into three regions $\left[0, k_{A}^{\prime}\right] \times\left\{k_{B}\right\} \subset K^{c},\left(k_{A}^{\prime}, k_{A}^{\prime \prime}\right] \times\left\{k_{B}\right\} \subset K_{1}^{d}$ and $\left(k_{A}^{\prime \prime}, a\right] \times\left\{k_{B}\right\} \subset K_{2}^{d}$. Figure 3 illustrates the spatial arrangement of $K^{c}, K_{1}^{d}$ and $K_{2}^{d}$ for Example 1.

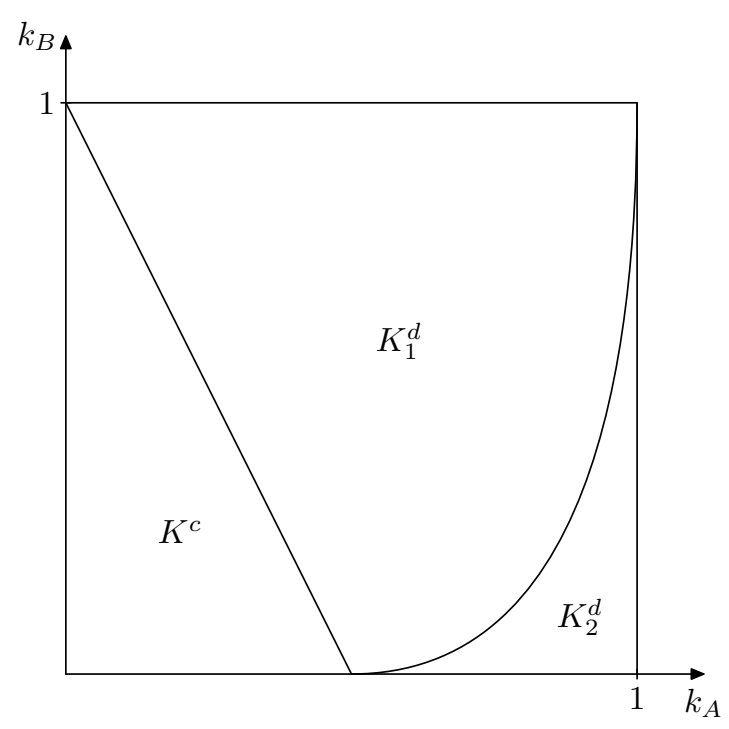

Figure 3: Set of capacities

Step 2. We show that the first-stage equilibrium capacities cannot lie in $K_{2}^{d}$.

If $k_{A} \leq D\left(p_{A}^{d}\right)$, then

$$
p_{A}^{d} k_{A}=p_{A}^{m}\left(D\left(p_{A}^{m}\right)-k_{B}\right) \Longleftrightarrow p_{A}^{d}=\frac{p_{A}^{m}\left(D\left(p_{A}^{m}\right)-k_{B}\right)}{k_{A}}
$$

while for $k_{A}>D\left(p_{A}^{d}\right), p_{A}^{d}$ is defined by the minimum price satisfying equality

$$
p_{A}^{d} D\left(p_{A}^{d}\right)=p_{A}^{m}\left(D\left(p_{A}^{m}\right)-k_{B}\right) .
$$

Note, however, that this latter case cannot be part of the equilibria, since $p_{A}^{d}$ given by (14) is independent of $k_{A}$, and for that reason the private firm could increase its profit by choosing a lower capacity level equal to $k_{A}^{\prime}=k_{A}-\varepsilon>D\left(p_{A}^{d}\right)$. Thus, in equilibrium $k_{A} \leq D\left(p_{A}^{d}\right)$ holds.

\footnotetext{
${ }^{14}$ Observe that in the strong private firm case $\pi_{A}^{r}\left(p_{A}^{m}\right)>0$ and $D\left(p_{A}^{m}\right)-k_{B}>0$.
} 
Step 3. We show that the first-stage equilibrium capacities cannot lie in $K_{1}^{d}$.

Given the equilibrium prices, for any capacity profile $\left(k_{A}, k_{B}\right)$ the firms' first-stage objective functions are

$$
\bar{\pi}_{A}\left(k_{A}, k_{B}\right)= \begin{cases}p_{A}^{d} k_{A}-C_{A}\left(k_{A}\right) & \text { if }\left(k_{A}, k_{B}\right) \in K^{d} \\ p^{c} k_{A}-C_{A}\left(k_{A}\right) & \text { if }\left(k_{A}, k_{B}\right) \in K^{c}\end{cases}
$$

and

$$
\bar{\pi}_{B}\left(k_{A}, k_{B}\right)= \begin{cases}\int_{0}^{D\left(p_{A}^{d}\right)} P(q) d q-C_{A}\left(k_{A}\right)-C_{B}\left(k_{B}\right) & \text { if }\left(k_{A}, k_{B}\right) \in K^{d}, \\ \int_{0}^{k_{A}+k_{B}} P(q) d q-C_{A}\left(k_{A}\right)-C_{B}\left(k_{B}\right) & \text { if }\left(k_{A}, k_{B}\right) \in K^{c} .\end{cases}
$$

For simplicity we did not substitute the already determined expressions for functions $p_{A}^{d}$ and $p^{c}$ in the objective functions.

Since solutions from $K^{c}$ and $K_{1}^{d}$ dominate the capacity levels from $K_{2}^{d}$ we focus our attention only on $K^{c}$ and $K_{1}^{d}$. However, by determining $\frac{\partial}{\partial k_{A}} \bar{\pi}_{A}\left(k_{A}, k_{B}\right)$ on the interior of $K_{1}^{d}$ we can exclude capacities belonging to $K_{1}^{d}$ as well. To see this, consider the private firm's profit function on the above mentioned interval:

$$
\bar{\pi}_{A}\left(k_{A}, k_{B}\right)=p_{A}^{d} k_{A}-C_{A}\left(k_{A}\right)=p_{A}^{m}\left(D\left(p_{A}^{m}\right)-k_{B}\right)-C_{A}\left(k_{A}\right),
$$

thus

$$
\frac{\partial}{\partial k_{A}} \bar{\pi}_{A}\left(k_{A}, k_{B}\right)=-C^{\prime}\left(k_{A}\right)<0 .
$$

Hence, $\pi_{A}$ is decreasing in $k_{A}$ on $K_{1}^{d}$ for any given $k_{B}$, which implies that the equilibrium solution is necessarily in $K^{c}$.

Step 4. We show that the unique equilibrium $\left(q_{A}^{*}, q_{B}^{*}\right)$ of the mixed Cournot duopoly lies in $K^{c}$ and satisfies the first-order condition of the first-stage of the mixed Kreps and Scheinkman game.

Notice that within $K^{c}$ the objective functions given by (15) and (16) are identical to (1) and (2) determined for the mixed Cournot duopoly case. We express the second period residual profit function defining $p_{A}^{m}$ in terms of quantities and maximize

$$
\pi_{A}^{r}\left(q_{A}\right)=P\left(q_{A}+k_{B}\right) q_{A}
$$

with respect to $q_{A}$, where $k_{B}=q_{B}^{*}$, and let $k_{A}=q_{A}^{*}$. The solution is denoted as $q_{A}^{m}$. For this problem the sufficient first-order condition yields

$$
P^{\prime}\left(q_{A}^{m}+k_{B}\right) q_{A}^{m}+P\left(q_{A}^{m}+k_{B}\right)=0 .
$$

Observe that $P\left(q_{A}^{m}+k_{B}\right)$ coincides with $p_{A}^{m}\left(k_{B}\right)$, since we have solved the same profit maximization problem in two different ways. Combining equation (17) and the first equation of (3), we get

$$
P^{\prime}\left(q_{A}^{m}+k_{B}\right) q_{A}^{m}+P\left(q_{A}^{m}+k_{B}\right)-C_{A}^{\prime}\left(k_{A}\right)<P^{\prime}\left(k_{A}+k_{B}\right) k_{A}+P\left(k_{A}+k_{B}\right)-C_{A}^{\prime}\left(k_{A}\right)=0
$$


by Assumption 2. Therefore, since function $P^{\prime}\left(q_{A}+k_{B}\right) q_{A}+P\left(q_{A}+k_{B}\right)$ is strictly decreasing in $q_{A}$ on $\left[0, a-k_{B}\right]$ by Assumption 1 it follows that $q_{A}^{m}>k_{A}$, which in turn implies that $p_{A}^{m}\left(k_{B}\right)=P\left(q_{A}^{m}+k_{B}\right)<P\left(k_{A}+k_{B}\right)$. Thus, $\left(q_{A}^{*}, q_{B}^{*}\right)$ lies in the interior of $K^{c}$.

Step 5. We show that the unique equilibrium of the mixed Cournot duopoly is indeed an equilibrium of the first-stage of the mixed Kreps and Scheinkman game.

As explained in Subsection 2.1 the first-order conditions given by (3) have a unique solution, now denoted by $\left(k_{A}^{*}, k_{B}^{*}\right)$, and thus the capacity-choice game can have at most one equilibrium in pure strategies with $\left(k_{A}^{*}, k_{B}^{*}\right)$ as the potential equilibrium solution. We check that $\left(k_{A}^{*}, k_{B}^{*}\right)$ is an equilibrium of the capacity-choice stage, which means that for both firms we have to exclude a unilateral and beneficial deviation in capacity falling into region $K^{d}$. Concerning the private firm, we have already seen that $\bar{\pi}_{A}\left(k_{A}^{*}, k_{B}^{*}\right)>\bar{\pi}_{A}\left(k_{A}, k_{B}^{*}\right)$ for any $\left(k_{A}, k_{B}^{*}\right) \in K^{d}$. Turning to the public firm, by increasing its capacity from $k_{B}^{*}$ until the boundary of $K^{c}$ decreases social welfare, and increasing $k_{B}$ even further results in lower social welfare than in case of the mixed Cournot duopoly since $p_{A}^{d}\left(k_{A}^{*}, k_{B}\right)>P\left(k_{A}^{*}, k_{B}\right)$ for any $\left(k_{A}^{*}, k_{B}\right) \in K^{d}$.

Informally, Theorem 1 means that quantity precommitment and Bertrand competition yield Cournot outcomes not only in duopolies with private firms (see Kreps and Scheinkman, 1983) but also in mixed duopolies.

\section{References}

Amir, R. and De Feo, G. (2014): Endogenous Timing in a Mixed Duopoly, International Journal of Game Theory, Vol. 43, No. 3, 629-658.

Bakó, B. and Tasnádi, A. (2014): A Kreps-Scheinkman állítás érvényessége lineáris keresletú vegyes duopóliumok esetén? (The Kreps and Scheinkman Result Remains Valid for Mixed Duopolies with Linear Demand), Közgazdasági Szemle, Vol. 61, No 5, 533-543 (in Hungarian).

Balogh, T.L. and Tasnádi, A. (2012): Does Timing of Decisions in a Mixed Duopoly Matter?, Journal of Economics, Vol. 106, No. 3, 233-249.

Beato, P. and Mas-Colell, A. (1984): The Marginal Cost Pricing as a Regulation Mechanism in Mixed Markets, in Marchand, M., Pestieau, P. and Tulkens, H. eds., The Performance of Public Enterprises, North-Holland, Amsterdam, 81-100.

Boccard, N. and Wauthy, X. (2000): Bertrand Competition and Cournot Outcomes: Further Results, Economics Letters, Vol. 68, No. 3, 279-285.

Boccard, N. and Wauthy, X. (2004): Bertrand Competition and Cournot Outcomes: A Correction, Economics Letters, Vol. 84, No. 2, 163-166. 
Cremer, H., Marchand, M. and Thisse, J.-F. (1989): The Public Firm as an Instrument for Regulating an Oligopolistic Market, Oxford Economic Papers, Vol. 41, No. 2, 283-301.

Davidson, C. and Deneckere, R. (1986): Long-Run Competition in Capacity, Short-Run Competition in Price, and the Cournot Model, Rand Journal of Economics, Vol. 17, No. 3, 404-415.

Deneckere, R. and Kovenock, D. (1992): Price Leadership, Review of Economic Studies, Vol. 59, No. 1, 143-162.

Deneckere, R. and Kovenock, D. (1996): Bertrand-Edgeworth Duopoly with Unit Cost Asymmetry, Economic Theory, Vol. 41, No. 1, 1-25.

de Fraja, G. and Delbono, F. (1989): Alternative Strategies of a Public Enterprise in Oligopoly, Oxford Economic Papers, Vol. 41, No. 2, 302-311.

de Frutos, M.-A. and Fabra, N. (2011): The Role of Demand Uncertainty, International Journal of Industrial Organization, Vol. 29, No. 4, 399-411.

George, K. and La Manna, M.M.A. (1996): Mixed Duopoly, Inefficiency, and Public Ownership, Review of Industrial Organization, Vol. 11, No. 6, 853-860.

Harris, R.G. and Wiens, E.G. (1980): Government Enterprise: An Instrument for the Internal Regulation of Industry, Canadian Journal of Economics, Vol. 13, No. 1, 125132.

Kreps, D.M. and Scheinkman, J.A. (1983): Quantity Precommitment and Bertrand Competition Yiels Cournot Outcomes, The Bell Journal of Economics, Vol. 14, No. 2, 326-337.

Lepore, J.J. (2009): Consumer Rationing and the Cournot Outcome, The B.E. Journal of Theoretical Economics, Vol. 9, No. 1 (Topics), Article 28.

Lepore, J.J. (2012): Cournot Outcomes under Bertrand-Edgeworth Competition with Demand Uncertainty, Journal of Mathematical Economics, Vol. 48, No. 3, 177-186.

Loertscher, S. (2008): Market Making Oligopolies, Journal of Industrial Economics, Vol. 56, No. 2, 263-289.

Merrill, W.C. and Schneider, N. (1966): Government Firms in Oligopoly Industries: A Short-run Analysis, Quarterly Journal of Economics, Vol. 80, No. 3, 400-412.

Osborne, M.J. and Pitchik, C. (1986): Price Competition in a Capacity-Constrained Duopoly, Journal of Economic Theory, Vol. 38, No. 2, 238-260.

Reynolds, S.S. and Wilson, B.J. (2000): Bertrand-Edgeworth Competition, Demand Uncertainty, and Asymmetric Outcomes, Journal of Economic Theory, Vol. 92, No. 1, 122-141. 
Tomaru, Y. and Kiyono, K. (2010): Endogenous Timing in Mixed Duopoly with Increasing Marginal Costs, Journal of Institutional and Theoretical Economics, Vol. 166, No. 4, $591-613$.

Vives, X. (1999): Oligopoly Pricing: Old Ideas and New Tools, MIT Press, Cambridge MA.

Wolfstetter, E. (1999): Topics in Microeconomics, Cambridge University Press, Cambridge UK.

Wu, Xin-wang, Zhu, Quan-tao and Sun, Laixiang (2012): On Equivalence Between Cournot Competition and the Kreps-Scheinkman Game, International Journal of Industrial Organization, Vol. 30, No. 1, 116-125. 